\title{
Avaliação da implementação do Programa Nacional de Fortalecimento da Agricultura Familiar - novas perspectivas de análise ${ }^{1}$
}

\author{
Felipe Barbosa Zani \\ Escola Brasileira de Administração Pública e de Empresas/Fundação Getulio Vargas (EBAPE/FGV) \\ Frederico Lustosa da Costa \\ Universidade Federal Fluminense (UFF)
}

\begin{abstract}
Este trabalho apresenta os resultados da avaliação da implementação do Programa Nacional de Fortalecimento da Agricultura Familiar (Pronaf) desenhada a partir dos eixos conteúdo, contexto, capacidade, compromisso e clientes/coalizões. Além de análise documental, foram realizadas entrevistas e grupos focais. Os resultados corroboram a necessidade de convergência entre as vertentes top-down e bottomup para a análise da implementação de políticas públicas e pontuam como entrave mais significativo ao êxito do programa as deficiências do sistema de assistência técnica. Por outro lado, observam-se expressivos avanços quanto à estrutura de governança, que possibilita o equacionamento das demandas portadas pelos diferentes atores e que fomenta atualizações constantes no escopo do programa, podendo assegurar a manutenção da qualidade operacional alcançada.
\end{abstract}

Palavras-chave: políticas públicas; implementação; avaliação formativa; Pronaf.

La evaluación de la implementación del Programa Nacional de Fortalecimento da Agricultura Familiar - nuevas perspectivas de análisis

Este trabajo presenta los resultados de la evaluación de la implementación del Pronaf realizada bajo los criterios de contenido, contextualización, capacidad, compromiso y clientes/coaliciones. Además

DOI: http://dx.doi.org/10.1590/0034-76121555

Artigo recebido em 25 abr. 2013 e aceito em 7 abr. 2014.

${ }^{1} \mathrm{O}$ presente artigo nasceu de uma reflexão sobre um projeto de assistência técnica realizado pela Fundação Getulio Vargas com o propósito de oferecer instrumentos e categorias de análise ao governo federal para a avaliação de programas públicos de subsídio ao crédito agrícola. Um trabalho anterior contou com a colaboração do prof. José Cezar Castanhar, coordenador do projeto de consultoria, a quem os autores agradecem a orientação técnica que permitiu os desenvolvimentos conceituais e empíricos posteriores aqui empreendidos. Uma versão muito preliminar foi apresentada no XXXV Encontro da Associação Nacional de Programas de Pesquisa e Pós-Graduação em Administração (ENANPAD 2011). O atual desenvolvimento é fruto de continuada colaboração entre os autores. 
del análisis documental, se realizaron entrevistas y grupos focales. Los resultados apuntan la necesitad de convergencia de las perspectivas top-down y bottom-up en el análisis de la implementación de políticas públicas e indican las deficiencias del sistema de asistencia técnica como la barrera más importantes para el éxito de dicho programa. Por otra parte, se observan significativos avances con relación a la estructura de gobernanza que posibilita el atendimiento de las demandas de los distintos actores y produce actualizaciones frecuentes en el formato del programa, lo que puede garantizar la manutención de la calidad operacional alcanzada.

Palabras clave: políticas públicas; implementación; evaluación formativa; Pronaf.

Evaluation of Programa Nacional de Fortalecimento da Agricultura Familiar implementation new perspectives of analysis

This paper presents the results of Pronaf's implementation evaluation based on the following criteria: content, context, capacity, commitment and clients/coalitions. Beyond the documental analysis, the methodology has used interviews and focus groups. The results highlight the necessity of convergence between the perspectives top-down and bottom-up for the analysis of implementation of public policies and indicate technical assistance deficiencies as the most important obstacles for the success of the program. On the other hand, there are meaningful improvements on the governance structure, enabling the settlement of demands brought up by different actors and that enhances frequent updates in the scope of the program, thus ensuring the maintenance of the operational quality achieved.

Keywords: public policies; implementation; formative evaluation; Pronaf.

\section{Introdução}

O Programa Nacional de Fortalecimento da Agricultura Familiar (Pronaf) foi instituído em 1996 na sequência de uma série de programas governamentais de apoio ao pequeno produtor rural que tinham como objetivo promover o desenvolvimento rural em regiões deprimidas ou de baixa renda.

A amplitude atual da política em questão ganha contornos nítidos em face dos mais de 14 milhões de contratos de crédito rural firmados entre 2003-10, que totalizaram aproximadamente 60 bilhões de reais em financiamento. Suas linhas de crédito beneficiam agricultores vinculados à reforma agrária, à agroecologia, à agroindústria, com linhas específicas para microagricultores, mulheres, jovens, dentre outros.

A magnitude do Pronaf justifica as sucessivas avaliações de que esse programa tem sido objeto, projetadas fundamentalmente para aferir seus resultados e impactos no contexto do desenvolvimento rural no que concerne à ampliação do acesso ao crédito rural, geração de emprego e renda etc.

Nesse contexto, toma-se, por exemplo, estudo conduzido por Mattei (2005) nos 100 municípios que mais contrataram crédito rural no período de 2001 a 2004, que constata a influência do Pronaf, dentre outros, sobre a elevação da produção agregada total e sobre a arrecadação municipal própria. 
Por outro lado, são incomuns as avaliações sobre o Pronaf voltadas à sua implementação, "the ability to forget subsequent links in the causal chain so as to obtain the desired results" (Pressman e Wildavky, 1973:xv), em que pese a estatura da referida política, mobilizadora de substanciais recursos orçamentários e sustentada por uma complexa rede de agentes públicos, privados e atores sociais.

Na verdade, grande parte dos estudos sobre políticas públicas, tributários da vertente analítica top-down, focam a fase de formulação da ação governamental, etapa racional e compreensiva, pressupondo a implementação como fase meramente linear guiada estritamente pela formulação. Não só os pesquisadores, mas também os burocratas brasileiros no nível federal (Puppim de Oliveira, 2006) assumem que o sucesso da política depende sobremaneira da conformidade do planejamento, a partir do qual alterações verificadas durante a implementação da política são entendidas como "desvios de rota".

Contudo, "as vicissitudes da implementação de programas governamentais têm sido entendidas como uma das dimensões cruciais — senão a variável central — para a explicação do insucesso dos governos em atingir os objetivos estabelecidos" (Neep, 1999:98).

Aceita a análise de que os "programas raramente são implementados de acordo com sua concepção original" (Neep, 1999:108), o presente trabalho revela os resultados de uma avaliação formativa (ou de processos) sobre a implementação do Pronaf desenhada com foco nos elementos referentes ao conteúdo, contexto, compromisso, capacidade e clientes/coalizões do programa em questão.

\section{Dilemas de cima a baixo na implementação de políticas públicas}

As políticas públicas são o produto do governo, mas sua construção é resultado de um complexo jogo social do qual participam inúmeros atores. Num texto em que introduz os conceitos básicos de política pública, Saravia (2006:32) apresenta as etapas do processo das políticas públicas — o canônico policy cycle — resumidamente identificado pelas fases de formulação, implementação e avaliação. O autor circunscreve essa construção teórica como "pouco mais que mero exercício de compreensão".

Embora haja razões pragmáticas para dividir o processo das políticas públicas em estágios, sua análise só teria a ganhar se superasse definitivamente essa lógica sequencial planejamento-implementação-avaliação. O modelo propugnado pelo referido ciclo de políticas supõe uma clara separação entre atividades de decisão e execução, entre tarefas de políticos e burocratas, como se as decisões políticas não levassem em conta parâmetros técnicos e as ações de administradores não tivessem nenhum sentido político. Na verdade, planejamento, implementação e avaliação fazem parte da "formação" da política (Lustosa da Costa, 1992:18), processo magmático cujos elementos constitutivos são de difícil identificação.

Na clássica visão do policy cycle, a dinâmica de implementação das políticas públicas é considerada de maneira estática e linear. A vontade política, traduzida em planos ou programas, seria automaticamente implementada de cima para baixo. Essa leitura, tributária da tradição top-down, focaliza a etapa de formulação e, a partir daí, reduz a análise aos mecanis- 
mos necessários para assegurar elevados níveis de fidelidade da implementação ao desenho inicial. Partindo do pressuposto de que a ação governamental é marcada, dentre outros, "pela informação perfeita, recursos ilimitados, coordenação perfeita, controle, hierarquia, clareza de objetivos", os problemas de implementação são entendidos como meros "desvios de rota" (Neep, 1999:101).

O estudo de situações concretas revela que são raras as situações nas quais os programas são implementados em completa sintonia com o desenho previsto por seus formuladores. Isso porque, a despeito da crença irrealista na possibilidade de garantir completa fidelidade da "política em ação" à "política formulada", o ciclo de políticas públicas é marcado por negociação, ambiguidade de objetivos, recursos limitados, informação escassa (Neep, 1999).

A leitura estreita da implementação como desdobramento inequívoco da etapa de formulação de políticas, embora endossado pela perspectiva top-down, também revela que a literatura de políticas públicas relegou por muito tempo a importância dessa etapa no ciclo de políticas públicas (Najam, 1995).

Somente na década de 1970 é publicado o trabalho seminal de Pressman e Wildavsky — Implementation —, que sublinha a importância da análise da implementação de políticas com base na observação do retumbante fracasso logrado por um programa de desenvolvimento econômico executado pelo governo norte-americano.

Assim, os debates travados em torno da questão da implementação orbitam em torno de duas correntes de pensamento principais - top-down e bottom-up - que se diferenciam quanto à perspectiva de análise do fluxo de decisões acerca das políticas públicas.

Os estudiosos da abordagem top-down, majoritariamente prescritiva, iniciam a análise sobre as políticas públicas nos níveis centrais do processo de tomada de decisão, com foco sobre os indivíduos revestidos de autoridade legal para a formulação de programas, e descem pela estrutura hierárquica visando a examinar em que grau os objetivos traçados foram alcançados e o nível de fidelidade da implementação em relação ao desenho da política (Najam, 1995). A atenção está voltada para a hierarquia formal da organização e para os mecanismos de controle e comunicação responsáveis por disseminar a política formulada no nível central para os demais agentes implementadores da cadeia (Barrett, 2004).

Nos anos iniciais da década de 1980, ganha força a matriz de análise bottom-up. Essa nova proposta, de corte descritivo, foca sua análise no universo de atores envolvidos na implementação da política no nível local/operacional. A perspectiva bottom-up critica o foco excessivo que sua antecessora concedia ao núcleo central dos tomadores de decisão e à estrutura racional-legal da organização, tendendo a negligenciar as interações organizacionais e os demais atores envolvidos na ação governamental ou a considerá-los simplesmente como empecilhos à implementação (Monteiro, 2004?; Najam, 1995; Sabatier, 1986).

As reflexões oferecidas por essa perspectiva permitem entender que as falhas na implementação de políticas públicas não são exclusivamente motivadas por "desvios de rota" em comparação ao desenho da ação governamental, mas que recursos, prioridades e influência dos implementadores variam ao longo do tempo, impactando sua disposição em colaborar com a execução do programa; que variações observadas durante a implementação podem decorrer da decisão própria dos agentes implementadores (Rorri e Freeman apud Neep, 1999); e 
que esses agentes, no nível operacional (street level bureaucracy), gozam de razoável margem de discricionariedade na oferta dos bens e serviços (Subirats, 1982). Nesses termos, a adesão da burocracia operacional à estratégia formulada pelos tomadores de decisão dependeria de estruturas de incentivos (Neep, 1999).

Fatalmente a abordagem bottom-up também foi alvo de críticas dos pesquisadores filiados à leitura top-down no que tange ao risco de enfatizar excessivamente o potencial dos atores periféricos em relação aos tomadores de decisão centrais ou mesmo quanto à sua incapacidade em sistematizar os fatores que afetam o comportamento dos diversos atores envolvidos no processo de implementação (Sabatier, 1986).

Em que pesem as diferenças apontadas entre as abordagens top-down e bottom-up, há razoável convergência entre os pesquisadores sobre a necessidade de combinar os méritos de ambas as abordagens quanto à análise das políticas públicas (Puppim de Oliveira, 2006; O’Toole, 1986).

Com base neste pressuposto, Najam (1995) constrói uma matriz analítica, denominada $5 C s$, que sintetiza um conjunto de cinco variáveis inter-relacionadas definidas a partir do acúmulo da literatura temática, tidas como determinantes do processo de implementação de políticas públicas.

Em sua proposta analítica, Najam (1995) parte do entendimento de que a implementação não é um mero problema administrativo, mas, como processo político intrinsecamente complexo, desenvolve-se por meio de uma complexa rede formada por múltiplos atores que operam em vários níveis. Em síntese, Najam (1995:34) conceitua a implementação "as a dynamic process of negotiation between multiple actors, operating and multiple levels, within and between multiple organizations".

A matriz proposta pelo autor considera cinco variáveis interconectadas, conforme ilustra a figura 1 , frequentemente identificadas por outros pesquisadores como variáveis-chave ao processo de implementação, quais sejam: (i) conteúdo, (ii) contexto, (iii) compromisso, (iv) capacidade e (v) clientes (ou beneficiários) e coalizações.

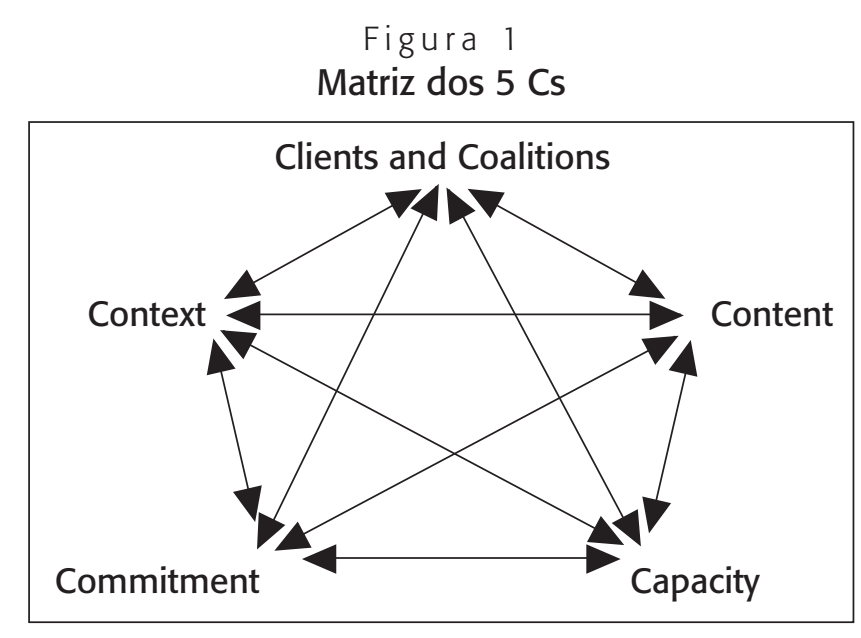

Fonte: Najam, 1995:35. 
A variável conteúdo preocupa-se com os objetivos da política; com a forma pela qual a questão central da política é problematizada, isto é, sua teoria causal; e com as estratégias formuladas para seu alcance. Embora fortemente vinculados, esses aspectos precisam ser considerados separadamente.

Por meio da variável contexto, Najam sugere a consideração dos aspectos sociais, econômicos, políticos e legais envoltos no ciclo de políticas públicas, mas direcionados às dinâmicas institucionais (ou interinstitucionais), para não transformar a análise numa verdadeira caixa preta que busca entender amplamente as variáveis de contexto.

No caso brasileiro, por exemplo, Abrúcio (2006) advoga a tese segundo a qual o federalismo pós-redemocratização demandou o estabelecimento de processos de negociação, coalizões, induções, isto é, processos de coordenação intergovernamental para assegurar a adesão dos governos locais às políticas federais.

A principal contribuição desta variável é a identificação dos atores institucionais centrais; das relações de poder e de interesses existentes entre e dentro destas instituições; e das mudanças às quais as instituições são submetidas para implementar a política e alcançar seus objetivos.

A variável compromisso, embora habitualmente vinculada à escola bottom-up, relacionase também com a "disposição" dos tomadores de decisão centrais em implementar a política. Mas existem diferenças entre ambas as abordagens. Pela vertente bottom-up o nível de compromisso dos implementadores seria decisivamente influenciado pelo contexto institucional e pelo comportamento dos beneficiários e coalizões. No caso da vertente top-down, o nível de compromisso é função do conteúdo da política e da provisão de capacidades (recursos) para implementá-la, elementos que podem ser controlados pelo topo.

A variável capacidade de implementação é unanimemente destacada pela literatura temática. A proposta de Najam é tratá-la como recursos administrativos que, basicamente, considerariam: tamanho e níveis de conhecimento das instituições de apoio; conhecimento sobre o problema e acesso a informações confiáveis para monitoramento; mecanismos de incentivo ou sanção ao comportamento; e estrutura física (tecnologia, instalações etc.).

Finalmente, enquanto as quatro variáveis tratadas até o momento focaram os mecanismos governamentais para a implementação de políticas, a variável beneficiários/coalizações mira os atores não estatais, sobretudo aqueles para os quais a política está focada, que podem acelerar, retardar ou direcionar a implementação, bem como os grupos de interesse que podem igualmente influenciar a política com posturas opositivas ou colaborativas. Deve-se mapear os atores mais influentes e analisar as estratégias que utilizam para impactar o curso da política em implementação.

Detalhada a matriz analítica construída por Najam, é adequado verificar sua aderência aos postulados formulados pelos pesquisadores da área. O’Toole (1986), após a análise de centenas de estudos temáticos, sintetiza as variáveis frequentemente apontadas pelos autores como cruciais ao processo de implementação: características da política (clareza e especificidade dos objetivos e procedimentos, validade da teoria causal) e disponibilidade de recursos. Outros fatores frequentemente aventados são as percepções dos agentes implementadores; alinhamento com os beneficiários; número de atores etc. 
Os achados de O'Toole reforçam o entendimento de que a construção de Najam abarca as variáveis determinantes para a análise do processo de implementação de políticas públicas, sendo, portanto, adotada neste estudo como referencial teórico para a avaliação de processos do Pronaf.

\section{Escopo e conteúdo da avaliação formativa}

Os estudos avaliativos preocupados com o funcionamento de determinada política são chamados de avaliação formativa (ou avaliação de processos ou avaliação da implementação). A avaliação formativa é realizada durante a implementação da política com foco em seu funcionamento, permitindo a realização de alterações para a melhoria do programa ainda durante sua execução (eficiência) (Cohen e Franco, 2004; Monteiro, 2004; Lustosa da Costa e Castanhar, 2003, Neep, 1999).

A literatura sobre avaliação, no entanto, apresenta significativas imprecisões conceituais. No Evaluation handbook da Fundação W. K. Kellogg, por exemplo, os autores não diferenciam a avaliação formativa do monitoramento. Na verdade, não parecem preocupados com conceitos mais precisos quando afirmam que "every project director has used implementation evaluation, whether or not they have labeled it as such" (W. K. Kellogg Foundation, 2005:24).

A constatação revela que a literatura sobre avaliação é composta por muitos manuais com conteúdo funcionalista, tecnicista, cujo interesse primordial é fornecer um roteiro operativo para a realização das avaliações valendo-se da sugestão de perguntas-chave, etapas, formulários padrão etc.

Tais manuais, em geral, tangenciam a discussão conceitual sobre a avaliação formativa/ avaliação de processos. Assim, prevalece o emaranhado conceitual, nas palavras de Lustosa da Costa e Castanhar (2003), manifestado na multiplicidade de conceitos, de tipologias de avaliação e de metodologias. E embora a avaliação formativa vise fornecer "informações para que a equipe do programa possa melhorá-lo" (Worthen, Sanders e Fitzpatrik, 2004:50), a existência de inadequações conceituais acarreta em "estudos de avaliação [que] não conseguem levar a melhorias significavas nos programas que julgam" (Worthen, Sanders e Fitzpatrik, 2004:57).

Assim, antes de investir esforços em buscar na literatura elementos que possam subsidiar o desenho metodológico da avaliação formativa, é necessário consolidar o seu entendimento.

Essa modalidade de avaliação é "an evaluation of the internal dynamics of implementing organizations, their policy instruments, their service delivery mechanisms, their management practices, and the linkages among these" (OCDE, 2002:30).

A avaliação de processos/formativa lida com a apreciação das estratégias, processos, etapas, estruturas adotadas na implementação de uma política visando à análise de três eixos principais de questões: (a) dos fatores condicionantes da eficiência da política, seus pontos fortes e fracos, barreiras e oportunidades (Monteiro, 2004?; Lustosa da Costa e Castanhar, 
2003; Rua, 1998); (b) do grau de adesão da implementação ao desenho original da política (Holanda, 2006; Monteiro, 2004?); e (c) da compatibilidade entre os mecanismos operativos da política e os resultados obtidos pelos formuladores (Cohen e Franco, 2004; Neep, 1999). Baseado nas definições aventadas no glossário da OCDE, o Handbook for development practitioners do Banco Mundial (Kusek e Rist, 2004) preocupa-se em diferenciar o monitoramento da avaliação.

Monitoring gives information on where a policy, program, or project is at any given time (and over time) relative to respective targets and outcomes. It is descriptive in intent. Evaluation gives evidence of why targets and outcomes are or are not being achieved. It seeks to address issues of causality. (OCDE, 2002:13; grifos no original)

Em decorrência (ou como consequência) da imprecisão conceitual que permeia a avaliação formativa (ou mesmo os estudos sobre a implementação de políticas, como visto anteriormente), Steckler e Linnan (2002) observam a falta de consenso sobre os componente-chave que devem guiar o planejamento e a realização dessas avaliações.

De fato, confirma-se a constatação anterior pela variedade de perguntas-chave sugeridas na literatura para a avaliação formativa, que dizem respeito à clareza e à compreensão dos objetivos da política, satisfação de seus beneficiários (Rua, 1998); aos obstáculos enfrentados, às lições aprendidas que podem ser apropriadas no processo de implementação (W. K. Kellogg Foundation, 2005); dentre outros tantas.

Partindo da constatação de que "program implementation is complex", Nightingale e Rossman (2010:331) avaliam que "conceptual models and frameworks help the evaluator stay organized and avoid information overload", embora "there is no one standard conceptual framework. Each study requires developing a framework (...)".

Este trabalho, portanto, estrutura-se a partir das reflexões teóricas propostas por Najam para a análise da dinâmica de implementação de políticas públicas e vale-se do conjunto de apontamentos da literatura sobre avaliação formativa, principalmente no que tange a seu escopo e procedimentos operacionais, para delinear o formato metodológico-operacional da avaliação pretendida.

\section{Metodologia da avaliação da implementação do Pronaf}

A avaliação de processos do Pronaf desenvolvida neste estudo, dentre os diferentes enfoques comportados pela avaliação de processos, teve como objetivo a "identificação das condições que propiciam ou entravam o processo de implementação do programa em análise" (Neep, 1999:152).

Em sua complexidade, o Pronaf mobiliza uma série de agentes ao longo do ciclo da política. Para este estudo, os agentes partícipes da política foram classificados em três categorias: formuladores, executores e beneficiários. 
A coleta de dados foi realizada entre 2009 e 2010 por meio de fontes de informação secundárias (documental e bibliográfica) e primárias, estas últimas obtidas em entrevistas telefônicas e presenciais, ambas semiestruturadas, e em grupos focais.

Inicialmente, analisaram-se os dados secundários com o objetivo de construir um cenário apriorístico acerca das condições de implementação do Pronaf que pudesse subsidiar as entrevistas posteriores.

Em um segundo momento, a coleta de dados secundários iniciou-se pela realização das entrevistas telefônicas com vista a validar as informações coletadas e subsidiar novos questionamentos por meio da construção de um panorama nacional.

Foram entrevistados representantes de 11 Secretarias Estaduais de Agricultura (PR, SC, BA, MA, GO, AC, CE, ES, MT, MS, TO), cujo sucinto roteiro de entrevista abordava as principais barreiras, êxitos e avanços nos últimos cinco anos relativos à operacionalização do crédito do Pronaf no respectivo estado.

As entrevistas presenciais, realizadas ao final das entrevistas telefônicas, tinham por objetivo qualificar e aprofundar as informações sobre a operacionalização do Pronaf obtidas nas fontes secundárias e nas entrevistas telefônicas.

No grupo dos formuladores foram realizadas entrevistas presenciais com representantes do Ministério do Desenvolvimento Agrário (SAF/MDA) e do Ministério da Fazenda (SPE/ $\mathrm{MF}$ ). No grupo dos executores foram realizadas entrevistas presenciais com representantes do MDA (Dater/SAF/MDA); do Tesouro Nacional (Copec/STN); do Banco do Brasil (DA/BB); além do Banco do Nordeste (BNB). Adicionalmente, realizou-se entrevista telefônica com o Banco da Amazônia (Basa).

Para o grupo dos beneficiários foi realizada entrevista telefônica, em virtude da impossibilidade de realizar a entrevista em Salvador (BA), com representante da Federação dos Trabalhadores na Agricultura Familiar (Fetraf).

Finalmente, foram realizados três grupos focais, nos quais puderam ser debatidos os mecanismos de governança, a adequabilidade do marco legal, o grau de satisfação com o atendimento que receberam dos agentes bancários, a qualidade da assistência técnica recebida, dentre outros, constituídos pelo seguinte perfil: Grupo 1: Beneficiários/Pernambuco; Grupo 2: Beneficiários/Rio Grande do Sul; e Grupo 3: Executores e Beneficiários/ Brasília.

Para a seleção dos municípios em que foram realizados os grupos focais 1 e 2 foram considerados o total de contratos do Pronaf firmados no triênio 2007-09 e a localização em diferentes regiões - Nordeste e Sul — dados os diferentes perfis apresentados pelos seus agricultores familiares.

Ao final da etapa de coleta de dados foi realizado o terceiro grupo focal em Brasília, constituído por nove participantes: (1) DA/BB, (2) BNB, (3) SPE/MF, (4; 5) Copec/STN, (6) SAF/MDA; e (7; 8; 9) Confederação Nacional dos Trabalhadores na Agricultura (Contag).

O quadro 1 esquematiza a metodologia adotada no estudo. 
Quadro 1

Síntese da estratégia de coleta de dados

\begin{tabular}{|c|c|c|c|}
\hline \multirow{2}{*}{ Categoria } & \multirow{2}{*}{ Agente } & \multicolumn{2}{|c|}{ Fonte dos dados } \\
\hline & & Primária & Secundária \\
\hline \multirow{2}{*}{ Formuladores } & SAF/MDA & Entrevista presencial & \multirow{2}{*}{$\begin{array}{c}\text { PPA/MDA - } 2004 \text { a } 2010 \\
\text { (ano-base) }\end{array}$} \\
\hline & SPE/MF & Entrevista presencial & \\
\hline \multirow{4}{*}{ Executores } & SEAs & Entrevista telefônica & \multirow{4}{*}{-} \\
\hline & Copec/STN/MF & Entrevista presencial & \\
\hline & Dater/SAF/MDA & Entrevista presencial & \\
\hline & BB/Basa/BNB & Entrevista presencial/telefônica & \\
\hline \multirow{2}{*}{ Beneficiários } & Agricultores Familiares & Grupo Focal (PE/RS) & \multirow{2}{*}{$\begin{array}{l}\text { Censo Agropecuário } 2006 \\
\text { Estudos avaliativos do Pronaf }\end{array}$} \\
\hline & Fetraf & Entrevista telefônica & \\
\hline Misto & - & Grupo Focal (Brasília) & - \\
\hline
\end{tabular}

Fonte: Elaboração dos autores.

\section{Avaliação de processos: o caso do Pronaf}

Os resultados da avaliação de processos do Pronaf foram agrupados pelos eixos analisados conforme tipologia proposta por Najam. Os dados apresentados entre colchetes referem-se à fonte da informação, discriminando a forma de coleta do dado e o agente responsável, quando aplicável.

As marcações em negrito dizem respeito aos principais tópicos analisados em cada eixo, resumidos no quadro 2 .

Quadro 2

\section{Elementos avaliados por eixo de análise}

\begin{tabular}{|c|c|}
\hline Conteúdo & $\begin{array}{l}\text { vefinição do público-alvo } \\
\text { v Amplitude dos objetivos do programa } \\
\text { v Teoria causal } \\
\text { v Metodologia de concessão do crédito }\end{array}$ \\
\hline Contexto & 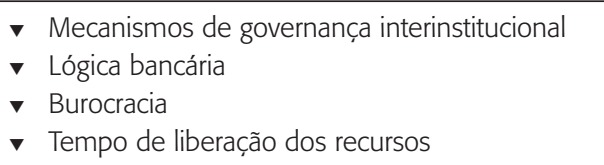 \\
\hline Capacidade & $\begin{array}{l}\text { Vstrutura do MDA } \\
\text { v Política de assistência técnica e extensão rural } \\
\text { v Inadimplência } \\
\text { v Estrutura e atendimento dos agentes bancários } \\
\text { v } \text { Custos administrativos do programa }\end{array}$ \\
\hline
\end{tabular}




\begin{tabular}{|c|c|}
\hline Compromisso & $\begin{array}{l}\text { V Estrutura e atuação do MDA/STN } \\
\text { V Contingenciamento de recursos } \\
\text { V Atuação dos extensionistas } \\
\text { V Atuação dos agentes bancários (Agroamigo) } \\
\text { V Atuação dos agentes responsáveis pela emissão da DAP }\end{array}$ \\
\hline Clientes/coalizões & $\begin{array}{l}\text { V Disputa pela definição legal de agricultor familiar (CNA) } \\
\text { V Mobilização dos movimentos sociais do campo (Contag/Fetraf) }\end{array}$ \\
\hline
\end{tabular}

Fonte: Elaboração dos autores.

\subsection{Eixo conteúdo: objetivos amplos para público diversificado}

A construção do Pronaf reflete, além da mobilização dos movimentos sociais do campo, a delimitação do grupo da agricultura familiar no início da década de 1990, antes genericamente denominado "pequeno agricultor". A consolidação gradual do programa levou à criação de sucessivas linhas de financiamento que diferenciavam este grande público da agricultura familiar em dezenas de subgrupos, fruto da permeabilidade da formulação da política às demandas portadas pelos movimentos sociais.

O próprio presidente Lula fica chamando o Pronaf de "sopa de letrinhas" e ele tem razão. O Pronaf hoje é um programa que deve ter o quê? Umas 20 linhas diferentes de crédito. [grupo focal: MDA]

Os críticos argumentam que essa fragmentação complica o entendimento da sistemática do programa entre os próprios agricultores, extensionistas e mesmo os agentes bancários que desconhecem grande parte das modalidades de crédito do Pronaf e acabam se especializando nas linhas de financiamento mais habituais.

Os defensores argumentam que a multiplicidade de linhas de crédito permite conferir tratamento diferenciado em termos de financiamento para um público muito heterogêneo. Além disso, a criação de linhas específicas como "mulher" ou "ovem", em que pese sua baixa expressividade quanto ao total de financiamento concedido, fomenta a busca de informações por públicos com pouca visibilidade no meio rural, favorecendo o protagonismo social.

Constantemente são adotadas medidas para facilitar o acesso ao crédito. Por exemplo, a simplificação das condições de enquadramento dos beneficiários anunciada no Plano Safra 2008-09 (agrupamento dos grupos C, D e E) permitiu reduzir a assimetria de informação e, consequentemente, ampliar o acesso ao crédito [Brasil, 2008].

Certamente a correta definição e dimensionamento do público-alvo privilegiado pelo Pronaf, sobretudo os segmentos mais empobrecidos, é condição incontornável para o alcance dos objetivos da política. E o Pronaf incorpora objetivos ambiciosos e abrangentes. Espera-se que, com a disponibilização do crédito rural, os agricultores fortaleçam sua capacidade produtiva, gerando emprego, renda e melhoria da qualidade de vida. Implicitamente, pretende- 
se a valorização do trabalho no campo, com impactos sobre a evasão rural, e o fomento ao desenvolvimento das regiões rurais.

Pressman e Wildavky (1973:xvi) alertam que "the longer the chain of causality, the more numerous the reciprocal relationships among the links and the more complex implementation becomes". A validação desta virtuosa, mas complexa, teoria causal ainda carece de avaliações somativas cujos resultados sejam conclusivos, condição indispensável para uma política social que mobiliza significativo montante financeiro.

Existem diferentes estudos avaliativos sobre os resultados do Pronaf (Ibase, 2006; Sei, 2002; Fecamp, 2002, dentre outros). É possível observar algumas convergências entre eles com relação aos avanços do Pronaf no que diz respeito ao associativismo local e ao incremento da produção e da produtividade dos agricultores beneficiados. Por outro lado, as avaliações não são conclusivas em relação aos impactos sobre a geração de emprego e renda, por exemplo, objetivo crucial da política.

Tais estudos também apontam para a dificuldade do programa no sentido de alterar o padrão de desenvolvimento agrícola vigente no país, rumo à construção de um modelo de desenvolvimento sustentável. Continua vigorando o viés produtivista baseado na utilização dos insumos modernos, especialmente fertilizantes químicos e agrotóxicos.

O método utilizado pelo Pronaf, qual seja, financiamento por produto, incentiva e reforça o padrão tradicional de produção. Em 2009 foi lançado o Pronaf Sustentável que, ao focar o financiamento na propriedade rural em sua totalidade, permite o desenvolvimento econômico dos agricultores familiares em paralelo ao desenvolvimento ecológico sustentável [Brasil, 2009, 2010].

\subsection{Eixo contexto: política social inserida na lógica bancária}

Em se tratando de um programa abrangente e complexo, o Pronaf envolve uma série de atores públicos, privados e da sociedade civil em sua formulação e operação, demandando o estabelecimento de um sistema de governança que evite o desajuste entre as atividades desenvolvidas por diferentes instâncias e que permita equacionar as demandas portadas pelos mais variados atores.

Os resultados revelam que são adequados os mecanismos de governança interinstitucional, de forma que a articulação entre os múltiplos atores é marcada pelo diálogo, inclusive entre agentes bancários e movimentos sociais, cuja relação no passado era mais conflitiva.

O acesso [entre os atores] é muito bom. A Fazenda recebe o MDA, o MDA recebe a Contag, os bancos... Há uma boa comunicação. [grupo focal: MDA]

De fato, é forte a presença dos movimentos sociais na construção do Pronaf, na qual prevalece a ideia de projeto coletivo. A participação dos beneficiários na condução da política via conselhos de desenvolvimento rural sustentável foi apontada como um aspecto positivo 
na construção e no acompanhamento da política [entrevista presencial: Fetraf; entrevista telefônica: MS, ES].

As instituições bancárias também participam ativamente na definição do desenho e do marco legal do Pronaf, o que contribui para a adequação do programa às realidades regionais, a exemplo da participação do Basa nas definições do Pronaf Floresta [entrevista presencial: Basa]. Essa construção coletiva da política, favorecida pela existência de arenas de diálogo entre os atores, estimula atualizações constantes no desenho e nas normas do Pronaf, como no lançamento do Pronaf Sustentável.

A operacionalização de uma política social por intermédio de instituições bancárias exigiu que o governo, mais do que a imposição legal, como no caso do Banco do Brasil, implantasse mecanismos de incentivos para que o Pronaf alcançasse o público menos estruturado da agricultura familiar.

O governo optou por assumir o risco das operações destinadas aos agricultores menos capitalizados [grupo focal: MF]. Além disso, a adaptação dos agentes bancários às operações de crédito rural, em particular do Pronaf, é resultado da pressão exercida pelos beneficiários (clientes) da política.

Embora possam burocratizar a obtenção dos financiamentos, os agentes bancários, por guardarem os aspectos legais e princípios financeiros (ex.: aversão ao risco) nas operações de crédito, reduzem a inadimplência, segundo defendem os formuladores da política. Ademais, sem a estrutura dos bancos, dificilmente o governo conseguiria atingir os mais pobres [entrevista presencial: MF].

Os bancos são atores parceiros que entram pra não virar um populismo orçamentário ou coisa do gênero. [grupo focal: MDA]

Em que pesem os argumentos que justificam a operacionalização do Pronaf por intermédio de agentes bancários, existe um conflito latente entre a lógica do mercado bancário, avessa ao risco e ávida por operações lucrativas, e a leitura que os movimentos sociais constroem acerca do Pronaf, preocupados muito mais com os efeitos sociais redistributivos da política do que com as obrigações assumidas com a obtenção de um empréstimo rural.

Vale destacar que as atividades bancárias estão sob a égide das regras oriundas dos Acordos de Basileia, voltadas para a promoção da estabilidade financeira. Assim, a atribuição de maior probabilidade de risco aos empréstimos rurais ocasiona maior necessidade de provisionamento de capital por parte das instituições financeiras, reduzindo e encarecendo a oferta de crédito.

Os entrevistados destacaram os problemas relacionados à burocracia bancária enfrentada na concessão do crédito, traduzida pelas garantias exigidas [entrevista telefônica: CE] e pelo tipo e excesso de documentação solicitada [entrevista telefônica: AC, CE, MA, MT, MS, RS, TO], na maioria dos casos não disponível pelo agricultor.

Diversos estudos corroboram os problemas burocráticos enfrentados pelos agricultores para a obtenção do crédito por conta de exigências bancárias (Ibase, 2006; Sei, 2002; Fe- 
camp, 2002). Por fim, segundo o Censo Agropecuário 2006 (IBGE, 2009), o segundo motivo pelo qual os agricultores não pleiteiam financiamento, depois do medo de contrair dívidas (59\%), é a burocracia (23\%).

Os agentes bancários afirmam que não há excesso na documentação exigida pelo banco para a avaliação dos clientes, indispensável dentro da lógica bancária, havendo margem para aumentar a cobrança de documentos. Contudo, assumem que essas exigências, por vezes, são usadas como subterfúgio para afugentar agricultores de maior risco.

Muitas vezes, em vez de o banco dizer para o agricultor que ele é arriscado e que não confia nele, vai dizer que o projeto está mal elaborado, que falta documentação. [entrevista presencial: BB]

Em alguns casos, contudo, a falta de documentação, a inadimplência, a irregularidade ambiental ou qualquer outra inadequação legal do agricultor adia a concessão do benefício ao agricultor que, sem entender as condições da política, atribui esse atraso ao excesso de burocratização por parte dos agentes bancários.

Os beneficiários, tanto no grupo focal de Pernambuco quanto no Rio Grande do Sul, bem como em diversos estudos (Ibase, 2006; Fecamp, 2002), reclamaram de atrasos na liberação dos recursos que, disponibilizados após a época de clima propício ao cultivo desejado, comprometem os investimentos. Foram criticados os prazos praticados pelos bancos para a liberação das parcelas e a demora para o repasse dos recursos aos agentes bancários pelo governo.

O atraso na liberação dos recursos pelos bancos aos agricultores não poderia, no cenário atual, ocorrer com os recursos do Tesouro Nacional, visto que não são alvo de contingenciamento se a STN trata essas operações com prioridade máxima, sendo os recursos liberados tão logo os bancos solicitam [entrevista presencial: STN]. Vale ressaltar, no entanto, que essa fonte de recursos é responsável por somente uma parcela do orçamento do Pronaf.

(...) houve uma evolução fantástica em termos de disponibilização (...). Dentro da esfera do governo, o Pronaf tem tantas prerrogativas favoráveis que não sofre contingenciamento (...). [grupo focal: STN]

Os motivos apontados para tais atrasos envolvem aspectos vinculados às diferentes variáveis do modelo de Najam. Em algumas agências bancárias, o gerente não programa adequadamente o fluxo de recursos do Pronaf pelo desinteresse (compromisso) com as operações rurais [entrevista presencial: $\mathrm{BB}$ ]. Os problemas com fluxos de recursos do banco por vezes estão relacionados à articulação interinstitucional (contexto) com os demais parceiros que compõem a operação.

Outras análises concluem que tais atrasos seriam motivados pelos procedimentos prévios ao repasse dos recursos aos bancos, que incluem a negociação com os movimentos sociais (clientes) sobre o orçamento disponível para a política e sobre as condições de acesso ao 
crédito que, embora legitimem as decisões sobre a política, atrasam a publicação das normas [grupo focal: diversos].

Por fim, não se pode ignorar que parte dos atrasos na liberação dos recursos possa ser motivada por problemas na documentação apresentada pelo agricultor (clientes) que, em alguns casos, desconhece o funcionamento da política e atribui a culpa ao agente bancário.

Os movimentos sociais e os executores do Pronaf, no entanto, avaliam que o processo de liberação do crédito melhorou substancialmente nos últimos anos, em razão da normatização tempestiva do Pronaf, seja por conta da antecipação das negociações com os movimentos sociais, da negociação célere entre os ministérios ou do aprendizado acumulado em relação à publicação dos atos normativos. Além disso, os bancos estruturaram superintendências exclusivas para as operações da agricultura familiar.

\subsection{Eixo capacidade: a (des)assistência técnica}

Enquanto o Ministério da Fazenda, nos últimos cinco anos, reforçou sua capacidade técnica para operar consistentemente no Pronaf [entrevista presencial: MF], os relatórios do Plano Plurianual, de forma geral, destacam a fragilidade da estrutura operacional do MDA.

A despeito da realização de concursos públicos no período 2004-08 visando à nomeação de servidores para o MDA, trata-se de um Ministério com pequeno quadro próprio de servidores. Além de reduzidas perante as responsabilidades de um programa do escopo do Pronaf, tanto a equipe gerencial quanto as equipes executoras do programa não possuem infraestrutura adequada para desempenhar suas atividades [Brasil, 2004, 2005, 2006a, 2006b, 2007].

A equipe responsável pelo Pronaf é composta principalmente por funcionários que ocupam cargos de livre nomeação e exoneração (DAS), além de consultores contratados por meio de projetos de cooperação técnica firmados com organismos internacionais. Embora sejam qualificados em termos de titulação e experiência, a instabilidade dos vínculos empregatícios desestimula investimentos na formação contínua dos funcionários. Outra fragilidade apontada é a inexistência de carreiras próprias do MDA [Brasil, 2005, 2006a, 2006b, 2007, 2008].

Em virtude do déficit de capacidade, a SAF/MDA executa a maioria das ações por meio de parcerias com órgãos estaduais e organizações não governamentais. E, em virtude da falta de pessoal, o tempo de tramitação dos convênios demandados no âmbito do Pronaf por vezes torna-se excessivamente longo. A publicação da Política Nacional de Assistência Técnica e Extensão Rural (Pnater) em 2010 modificou de convênio para chamada pública a forma de contratação das organizações públicas ou privadas responsáveis pela Ater, visando a garantir o fornecimento desses serviços de forma continuada [Brasil, 2010].

A assistência técnica figura como significativa, se não a principal, barreira para implementação do Pronaf [entrevista telefônica: MA, MT, GO, PR]. Apesar de os agricultores ainda sofrerem com a desarticulação pela qual a assistência técnica foi submetida, houve o reconhecimento de que a política da Ater vem sendo fortalecida nos últimos anos [entrevista telefônica: BA, SC, MA, PR]. 
Os relatórios de avaliação do PPA enfatizam a reestruturação do sistema nacional de assistência técnica, via aporte de recursos, contratação de técnicos, credenciamento de entidades, criação de redes temáticas e qualificação dos profissionais [Brasil, 2004, 2005, 2006a, 2006b, 2007].

Os esforços de organização do sistema da Ater, porém, esbarram na descontinuidade dos recursos, na insuficiência orçamentária em face da demanda dos agricultores familiares por assistência [Brasil, 2006a, 2006b, 2007] e no contingenciamento de recursos [Brasil, 2010].

As deficiências da política da Ater ocasionam sérios problemas ao Pronaf. Em virtude das fragilidades da Ater, alguns integrantes dos grupos focais sul rio-grandense e pernambucano manifestaram certo desconhecimento sobre a institucionalidade do programa, seus objetivos e sua lógica de funcionamento.

Eu conheço gente que financiou e achou que não precisava pagar. E quando soube que tinha que pagar ficou surpreso. [grupo focal: beneficiário/RS]

Os agricultores reclamam da falta de divulgação sobre o Pronaf por parte dos bancos e autoridades públicas (Sei, 2002; Fecamp, 2002). A ausência de acompanhamento técnico associada à falta de informações sobre o programa propicia sua captura política por atores sociais como lideranças locais, sindicais etc. e torna o agricultor dependente da ação de intermediários (associações) para acessar os financiamentos e mediar sua relação com os agentes bancários.

O presidente da associação é que resolve tudo, inclusive qual é o banco que a gente deve ir. [grupo focal: beneficiário/PE]

Nos grupos focais, os agricultores pernambucanos criticaram a assistência técnica, cujos problemas reduzem as possibilidades de êxito na produção na proporção em que aumentam o risco da inadimplência. Há falhas na transmissão de informações sobre as culturas mais adequadas, os riscos decorrentes das intempéries, o controle de pragas.

Além disso, sem assistência técnica adequada e, consequentemente, com falhas de informação, algumas políticas vinculadas ao Pronaf, como os seguros agrários, só chegam aos estratos mais estruturados do público-alvo.

Com isso, os agricultores nordestinos relataram que a frustração das safras dificulta a quitação dos financiamentos e, em não tendo firmado contratos de seguro que os reembolse pela perda total da produção, possivelmente ficarão inadimplentes. Assim, avaliam ser reduzidos os resultados da política na melhoria de suas condições socioeconômicas. Mesmo quando há melhoria, os agricultores nem sempre se dão conta da importância do programa [grupo focal: beneficiário/PE].

Eu não vi muita melhoria não. Antes estava ruim, mas eu não estava endividado. Eu tirei pra macaxeira que apodreceu todinha! [grupo focal: beneficiário/PE] 
A inadimplência não foi tratada pelos executores do Pronaf como problema crucial na alçada do programa. Nas regiões Norte e Nordeste as causas estariam mais relacionadas à falta de tecnologia e de infraestrutura, vinculada à frustração das safras e da falta de assistência técnica. Já nas regiões Sul e Sudeste, uma das causas do inadimplemento seria a influência ideológica dos movimentos sociais [entrevista presencial: BB]. Em alguns casos, os agricultores consideram o programa como programa assistencialista nos moldes de uma política social, em vez de um programa de crédito rural regido por normas bancárias. Em outros, são incentivados a não pagar porque o financiamento do Pronaf não seria um financiamento ou pela promessa futura de perdão da dívida.

Alguns dizem que o dinheiro é do Lula ou de outro candidato a deputado que colocou em outdoor "lutarei pelo perdão da dívida". [entrevista presencial: MDA]

Foram citados alguns problemas na estruturação dos agentes bancários, tanto em termos de capacitação específica dos funcionários para as operações do Pronaf e análise dos projetos [entrevista telefônica: PR, SC], quanto em relação ao descompasso entre o número de funcionários de algumas agências e o grande número de agricultores [entrevista telefônica: CE, GO, MS, RS, TO, PR], ou ainda em relação à dificuldade de acesso nos casos de municípios que não possuem agentes bancários credenciados, o que obriga os agricultores a percorrerem grandes distâncias [entrevista telefônica: MA, GO]. Também foram relatados casos de venda casada de produtos [entrevista telefônica: PR].

Alheios a estas fragilidades estruturais, os beneficiários avaliaram positivamente a cordial relação com os agentes bancários, dos quais receberam as orientações necessárias para a obtenção do crédito e que podem sopesar as falhas da Ater.

O PPA 2006 ressalta o ganho de eficiência do Pronaf, a partir de ações de parceria dos agentes financeiros com o MDA, que resultaram na redução dos custos com equalização, além da modificação de procedimentos administrativos.

Os custos com equalização reduziram significativamente desde o início do programa por conta da aquisição de expertise pelos bancos, que ganharam em escala, bem como pelas negociações relacionadas à remuneração das fontes. Com isso, os custos do programa foram diminuindo ao longo dos anos, alcançado um patamar adequado ao panorama atual [grupo focal: MF].

\subsection{Eixo compromisso: a discricionariedade burocrática}

O compromisso dos agentes implementadores deve ser analisado no nível central da política (Ministérios), mas, principalmente, no nível da street level bureaucracy, no qual se pode examinar o comprometimento dos extensionistas, do corpo funcional vinculado às instituições bancárias, bem como dos agentes responsáveis pela emissão da DAP. 
No nível central da política, o crescente volume de recursos com a consequente ampliação do público beneficiado fornece indícios sobre o comprometimento do governo com o Pronaf. Além disso, como fora mencionado anteriormente, a presença maciça de consultores no $M D A$, oriundos de instituições voltadas à defesa da agricultura familiar, como o Instituto Interamericano de Cooperação para a Agricultura (Iica), fortalece e qualifica o compromisso do MDA em relação ao Pronaf. Por fim, segundo afirma a STN, os recursos do Tesouro Nacional destinados ao crédito rural não são alvo de contingenciamento e as operações para sua liberação são consideradas prioritárias.

Por outro lado, a recorrência com a qual foram citados os problemas no fluxo de recursos financeiros [Brasil, 2004, 2005, 2007, 2010] parece revelar certa falta de comprometimento com as atividades da Ater.

O contingenciamento e o atraso na liberação de recursos, ao prejudicar a celebração de convênios e contratos de repasse, parecem impactar principalmente as ações de assistência técnica, dado que a elaboração dos projetos de crédito e as ações relativas à diversificação da produção e correta aplicação dos recursos, típicas da Ater, requerem acompanhamento regular.

Quanto à street level bureaucracy, no modelo atual da Ater, o extensionista não tem envolvimento/compromisso com o crédito concedido, não é avaliado e não é remunerado conforme seu desempenho. O Pronaf Sustentável, por sua vez, propõe remunerar o técnico com base nos resultados obtidos pelos agricultores atendidos, além de focar a avaliação da assistência prestada, objetivando elevar o comprometimento do técnico [entrevista presencial: MDA].

Os agentes bancários, via de regra, desempenham as tarefas relativas ao Pronaf em observância aos princípios financeiros, embora possam valer-se da burocratização para desestimular os empréstimos mais arriscados. Ou seja, mesmo submetidos aos rigorosos mecanismos de controle do sistema financeiro, em consonância ao que preconiza a vertente top-down, os agentes bancários possuem relativa margem de discricionariedade na implementação da política.

A exceção fica por conta do Agroamigo, programa orientado por metodologia específica para atender o setor rural, que é o grande destaque do Banco do Nordeste para operacionalizar o Pronaf. Criado em 2005, trata-se do maior programa de microfinança rural da América do Sul e atende a agricultores do Nordeste e do norte de Minas Gerais enquadrados no Pronaf.

A metodologia desse programa pauta-se na orientação para o crédito junto ao produtor; crédito sequencial e gradual; e acompanhamento do crédito após o financiamento; o que explica a centralidade do papel desempenhado pelos assessores de microcrédito [entrevista presencial - BNB].

Quanto aos agentes responsáveis pela concessão da $D A P$, geralmente instituições alinhadas com a causa da agricultura familiar (sindicatos, associações etc.), na ausência de mecanismos de fiscalização, gozam de grande discricionariedade na sua concessão, cabendo a eles definir sobre quais agricultores estão habilitados a acessar o crédito do Pronaf.

Embora os beneficiários não tenham apontado dificuldades na obtenção da DAP, foram identificados problemas em seu processo de concessão: pulverização das entidades credencia- 
das a emitir a DAP em paralelo à fragilidade dos mecanismos de fiscalização, reforçada por dificuldades de natureza tecnológica (acesso à internet), pelo extenso prazo de vigência da declaração, e por deficiências estruturais do MDA, principalmente em relação ao tamanho do seu quadro de servidores para acompanhar o processo [grupo focal: MDA, MF, Contag].

\subsection{Eixo clientes/coalizões: "hoje os grandes querem as condições do Pronaf"}

O Pronaf, como já fora abordado neste documento, é fruto das lutas políticas articuladas pelos movimentos sociais do campo em torno da reivindicação por ações governamentais específicas para os agricultores familiares. A própria criação do MDA, em 2003, é resultado dessa articulação, de tal sorte que o Ministério é permeável às demandas apresentadas pelos agricultores familiares.

Mas a força dos movimentos sociais convive com o desconhecimento de parte dos agricultores familiares sobre o Pronaf, mesmo daqueles que já obtiveram financiamentos do programa. Motivado pela heterogeneidade que marca a população do campo e agravado pela desestruturação da política de assistência técnica, essas falhas de informação sobre a política podem fragilizar a mobilização dos movimentos sociais.

Pronaf é alguma coisa de agricultura familiar, mas o que exatamente eu não sei. [grupo focal: beneficiários/PE]

Por se tratar de uma política de conteúdo redistributivo, o Pronaf desperta o interesse de coalizões vinculadas à agricultura que não são contempladas pelo programa em virtude dos critérios de elegibilidade relativos à definição de agricultor familiar (não dispor de área superior a quatro módulos fiscais; utilizar trabalho familiar etc.).

A Confederação da Agricultura e Pecuária do Brasil (CNA), entidade que defende as bandeiras dos agropecuaristas patronais, encomendou dois estudos que, com base nos microdados do Censo Agropecuário 1995-96 e 2006, concluem pela inadequação das normas responsáveis por ditar os grupos com direito de receber o financiamento subsidiado do Pronaf. Categorizados entre agricultores enquadráveis e não enquadráveis, o estudo conclui que

os pequenos e médios produtores não enquadráveis representam um modelo mais viável economicamente. Portanto, sugere a necessidade de outra tipificação dos produtores, que leve menos em conta o tamanho do estabelecimento ou o número de trabalhadores permanentes contratados, mas a renda bruta gerada, como já ocorre em outros países. (CNA e FGV, 2004:159)

A CNA possui significativo poder de influência na política nacional considerando seu grau de institucionalização, a presença de lideranças políticas no movimento e sua trajetória política. Por outro lado, o Pronaf é fruto das lutas reivindicatórias encampadas pelos movimentos sociais representantes dos beneficiários, como a Contag e a Fetraf, e que, por sua 
capilaridade e poder de mobilização, podem contrabalancear a influência exercida pela CNA. De todo modo, a contratação do estudo expressa a estratégia desta confederação de legitimar tecnicamente seu pleito, recurso por vezes indisponível aos movimentos sociais.

Essa disputa pelo significado normativo de agricultor familiar, decorrente do interesse de alargar a abrangência do Pronaf para contemplar segmentos mais capitalizados dos agricultores, corrobora a afirmação de que "até pouco tempo todo pronafiano queria ter as condições dos grandes. Hoje os grandes querem as condições do Pronaf' [grupo focal: MF], e pode representar grandes impactos na política.

O Pronaf foi desenhado, a priori, para conceder empréstimos de valores mais modestos para agricultores que historicamente foram alijados do sistema financeiro. Essa condição permitiu a criação de diversos incentivos no âmbito da política, como programa de garantia de preços, juros baixos, menor fiscalização, dado que os riscos eram pequenos em virtude dos financiamentos com valores reduzidos. A incorporação, já em curso, de agricultores mais estruturados, que exigem empréstimos mais robustos, pode demandar a revisão dessas facilidades [grupo focal: MF].

Em contrapartida, possíveis reduções no custo financeiro do Pronaf, decerto pequenas, haja vista que estão perto do limite mínimo, dependerão da composição futura dos perfis dos agricultores familiares beneficiados. $\mathrm{O}$ aumento da participação dos agricultores mais estruturados, que absorvem financiamentos maiores, poderá significar redução nos custos [entrevista presencial: MF].

\section{Conclusões}

Os estudos que pretendem avaliar a implementação do Pronaf devem partir da constatação de que se trata de uma complexa política de âmbito nacional. Nesse sentido, uma avaliação ortodoxamente top-down poderia indicar que, embora os objetivos da política sejam claros, sua abrangência pode roubar-lhes consistência. Sua teoria causal seria carente de comprovação e composta por muitos elos em uma corrente extensa. Além disso, são débeis as estruturas de incentivo para assegurar a fidelidade dos extensionistas e das organizações emissoras da DAP em relação aos objetivos do programa, sem que se ignorem os esforços recentes capitaneados pela publicação da Pnater.

De positivo, o programa desfruta de apoio ministerial, tanto na área da agricultura familiar (MDA) quanto na área econômica (STN/MF), e vale-se da inserção do Pronaf na lógica bancária como mecanismo de controle e coordenação dos objetivos da política.

Tal leitura poderia atribuir elevados riscos à implementação do Pronaf em vista das fragilidades vinculadas aos objetivos, à disseminação de informações e à coordenação da política, elementos centrais para a leitura top-down.

Mas a ortodoxia top down, preocupada exclusivamente com a política formulada e com os níveis centrais da implementação, ignora, por exemplo, que os agentes bancários, mesmo 
sob o jugo das regras do mercado financeiro, podem utilizar-se da margem de discricionariedade para burocratizar a concessão de financiamento aos agricultores menos estruturados.

O acréscimo dos eixos analíticos preconizado pela vertente bottom-up permite observar que o programa conta com o apoio de expressivos movimentos sociais vinculados à causa da agricultura familiar, responsáveis pela construção de consensos em torno dos objetivos do Pronaf bem como pelo fortalecimento do próprio MDA, conferindo legitimidade política e técnica ao programa.

A consideração dos grupos de interesse na análise revela que a definição do públicoalvo, ou melhor, do que se entende por agricultor familiar, ainda é um debate em aberto, vistos os esforços empreendidos pelo CNA para inserir agricultores mais capitalizados como beneficiários do Pronaf.

Assim, uma avaliação que combine ambas as vertentes analíticas, como aquela delineada pela matriz de Najam, informa que o conteúdo do Pronaf é caracterizado por amplos objetivos, refletindo em uma teoria causal dilatada, mas cujos níveis de alinhamento na fase de implementação podem ser incrementados em função da inserção do programa na lógica bancária e da mobilização dos movimentos sociais, que reflete sobre a construção de consensos e sobre o comprometimento de agentes implementadores, como o MDA e os próprios bancos.

Os entraves que ainda persistem dizem respeito ao déficit institucional do MDA e à desestrutura do sistema de assistência técnica, em que pesem os esforços de fortalecimento desta política nos últimos anos.

Essas são deficiências vinculadas à capacidade de implementação do Pronaf e que limitam o alcance de seus objetivos. As deficiências no acompanhamento técnico dos agricultores na elaboração dos projetos e na aplicação do crédito, principalmente, podem provocar desequilíbrios regionais na distribuição dos financiamentos, utilização de técnicas inadequadas pelos agricultores, falta de informação acerca do funcionamento do programa e das políticas vinculadas.

Tais fatores desestruturam as condições econômicas e produtivas dos beneficiários do Pronaf, permitem a captura política do programa por atores locais e podem aumentar a inadimplência, motivos para a burocratização do acesso ao crédito e para redução da percepção, pelos beneficiários, sobre os resultados do programa.

Os resultados indicam significativos avanços na execução do Pronaf em termos da redução dos custos financeiros e operacionais; do atendimento dos agentes bancários, que podem minorar as falhas de informação provadas pela desestruturação da Ater, a despeito de carências estruturais (capacitação dos funcionários, número de agências etc.); e da construção de uma estrutura de governança que permita o equacionamento das atividades e demandas portadas pelos diferentes atores envoltos nessa complexa política.

De fato, o destaque do processo de implementação do Pronaf reside em seu contexto interinstitucional. A interação entre diferentes atores para o desenvolvimento da política, incluindo movimentos sociais, órgãos públicos e agentes bancários, fomenta atualizações constantes no escopo do programa, comprovada pela recente publicação da Pnater ou do Pronaf 
Sustentável, mas também pela criação do Agroamigo pelo Banco do Nordeste, e pode assegurar a manutenção do patamar de qualidade operacional alcançado pelo Pronaf.

\section{Referências}

ABRÚCIO, Fernando L. Para além da descentralização: os desafios da coordenação federativa no Brasil. In: FLEURY, Sônia (Org.). Democracia, descentralização e desenvolvimento: Brasil e Espanha. Rio de Janeiro: Editora FGV, 2006.

BARRETT, Susan M. Implementation studies: time for a revival? Personal reflections on 20 years of implementation studies. Public Administration, Oxford, v. 82 n. 2, p. 249-262, jun. 2004.

BRASIL. MINISTÉRIO DO PLANEJAMENTO, ORÇAMENTO E GESTÃO. Secretaria de Planejamento e Investimentos Estratégicos. Plano Plurianual 2004-2007: relatório anual de avaliação — ano base 2004/exercício 2005. Caderno 16: Ministério do Desenvolvimento Agrário. Brasília: MPOG, 2006.

BRASIL. MINISTÉRIO DO PLANEJAMENTO, ORÇAMENTO E GESTÃO. Secretaria de Planejamento e Investimentos Estratégicos. Plano Plurianual 2004-2007: relatório anual de avaliação — ano base 2005/exercício 2006. Caderno 16: Ministério do Desenvolvimento Agrário. Brasília: MPOG, 2006.

BRASIL. MINISTÉRIO DO PLANEJAMENTO, ORÇAMENTO E GESTÃO. Secretaria de Planejamento e Investimentos Estratégicos. Plano Plurianual 2004-2007: relatório anual de avaliação — ano base 2006/exercício 2007. Caderno 16: Ministério do Desenvolvimento Agrário. Brasília: MPOG, 2007.

BRASIL. MINISTÉRIO DO PLANEJAMENTO, ORÇAMENTO E GESTÃO. Secretaria de Planejamento e Investimentos Estratégicos. Plano Plurianual 2004-2007: relatório anual de avaliação — ano base 2007/exercício 2008. Caderno 16: Ministério do Desenvolvimento Agrário. Brasília: MPOG, 2008.

BRASIL. MINISTÉRIO DO PLANEJAMENTO, ORÇAMENTO E GESTÃO. Secretaria de Planejamento e Investimentos Estratégicos. Plano Plurianual 2008-2011: relatório anual de avaliação — ano base 2008/exercício 2009. Ministério do Desenvolvimento Agrário. Brasília: MPOG, 2010.

BRASIL. MINISTÉRIO DO PLANEJAMENTO, ORÇAMENTO E GESTÃO. Secretaria de Planejamento e Investimentos Estratégicos. Plano Plurianual 2008-2011: relatório anual de avaliação — ano base 2009/exercício 2010. Ministério do Desenvolvimento Agrário. Brasília: MPOG, 2011.

COHEN, Ernesto; FRANCO, Rolando. Avaliação de projetos sociais. 6. ed. Petrópolis: Vozes, 2004.

CONFEDERAÇÃO DA AGRICULTURA E PECUÁRIA DO BRASIL (CNA); FUNDAÇÃO GETULIO VARGAS (FGV). Quem produz o que no campo: quanto e onde. Brasília: CNA, 2004. (Coletânea Estudos Gleba; 34).

FUNDAÇÃO DE ECONOMIA DE CAMPINAS (FECAMP). Estudos de caso em campo para avaliação dos impactos do Pronaf. Campinas, SP: s.n., 2002. Convênio PCT/IICA-Pronaf e Fundação de Economia de Campinas (Fecamp).

HOLANDA, Nilson. Avaliação de programas. Conceitos básicos sobre a avaliação "ex post" de programas e projetos. Fortaleza: ABC Editora, 2006. 
INSTITUTO BRASILEIRO DE ANÁLISES SOCIAIS E ECONÔMICAS (IBASE). Relatório Pronaf: resultados da etapa Paraná. Rio de Janeiro: Ibase, 2006. Disponível em: <www.mda.gov.br/saf/ arquivos/0834315314.pdf>. Acesso em: 7 ago. 2009.

INSTITUTO BRASILEIRO DE GEOGRAFIA E ESTATÍSTICA (IBGE). Censo Agropecuário 2006. Rio de Janeiro: IBGE, 2009.

KUSEK, Jody Z.; RIST, Ray C. A handbook for development practitioners: ten steps to a results based monitoring and evaluation system. Washington: World Bank, 2004.

LUSTOSA DA COSTA, Frederico. A persistência da desigualdade. Fortaleza: Banco do Nordeste do Brasil, 1992.

LUSTOSA DA COSTA, Frederico; CASTANHAR, José C. Avaliação de programas públicos: desafios conceituais e metodológicos. Rev. Adm. Pública, Rio de Janeiro, v. 37, n. 5, p. 969-992, set./out. 2003.

MATTEI, Lauro. Impacto do Pronaf: análise de indicadores. Brasília: Ministério do Desenvolvimento Agrário, Núcleo de Estudos Agrários e Desenvolvimento Rural, 2005.

MONTEIRO, Geraldo T. M. Formulação e análise de políticas públicas. FGV Management — Cursos de educação continuada. s.1.: 2004? Mimeografado.

NAJAM, Adil. Learning from the literature on policy implementation: a synthesis perspective. Luxemburgo: International Institute for Applied Systems Analysis, 1995.

NIGHTINGALE, Demetra S.; ROSSMAN, Shelli B. Collecting data in the field. In: WHOLEY, Joseph S.; HATRY, Harry P.; NEWCOMER, Kahtryn E. (Org.). Handbook of practical program evaluation. 3. ed. São Francisco: Jossey-Bass, 2010.p. 321-346.

NÚCLEO DE ESTUDOS DE POLÍTICAS PÚBLICAS (NEPP/UNICAMP). Modelo de avaliação de programas sociais prioritários: relatório final. Campinas, 1999.

ORGANIZAÇÃO DE COOPERAÇÃO E DE DESENVOLVIMENTO ECONÔMICO (OCDE). Glossary of key terms in evaluation and results based management. Paris: OECD/DAC, 2002.

O'TOOLE, Laurence J. Policy recommendations for multi-actor implementation: an assessment of the field. Journal of Public Policy, Cambridge, v. 6, n. 2, p. 181-210, abr. 1986.

PRESSMAN, Jeffrey; WILDAVSKY, Aaron. Implementation. Berkeley: University of California Press, 1973.

PUPPIM DE OLIVEIRA, José A. Desafios do planejamento em políticas públicas: diferentes visões e práticas. Rev. Adm. Pública, Rio de Janeiro, v. 40, n. 2, p. 273-288, mar./abr. 2006.

RUA, Maria G. Política pública e políticas públicas no Brasil: conceitos básicos e achados empíricos. In: RUA, Maria G.; CARVALHO, Maria I. V. O estudo da política: tópicos selecionados. Brasília: Paralelo 15, 1998.

SABATIER, Paul A. Top-down and bottom-up approaches to implementation research: a critical analysis and suggested synthesis. Journal of Public Policy, Cambridge, v. 6, n. 1, p. 21-48, jan. 1986. 
SARAVIA, Enrique. Introdução à teoria da política pública. In: SARAVIA, Enrique; FERRAREZI, Elisabete (Org.). Políticas públicas. Coletânea. Brasília: Enap, 2006. 2 v.

STECKLER, Allan; LINNAN, Laura. Process evaluation for public health interventions and research. São Francisco: Jossey-Bass, 2002.

SUBIRATS, Joan. El papel de la burocracia en el proceso de determinación e implementación de las políticas públicas. In: SARAVIA, Enrique; FERRAREZI, Elisabete. O processo decisório de política. Rio de Janeiro: Ipea, 1982.

SUPERINTENDÊNCIA DE ESTUDOS ECONÔMICOS E SOCIAIS DA BAHIA. Avaliação do Pronaf Crédito na Bahia. 2002. In: MATTEI, Lauro. Pronaf 10 anos: mapa da produção acadêmica. Brasília: MDA, 2006. CD-ROM.

W. K. KELLOGG FOUNDATION. Evaluation handbook. 2005. Disponível em: <www.wkkf.org/ knowledge-center/resources/2010/W-K-Kellogg-Found. aspx> . Acesso em: 10 out. 2011.

WORTHEN, Blaine R.; SANDERS, James R.; FITZPATRICK, Jody L. Avaliação de programas: concepções e práticas. São Paulo: Gente, 2004.

Felipe Barbosa Zani é mestre em administração pública e pesquisador da Escola Brasileira de Administração Pública e de Empresas da Fundação Getulio Vargas (EBAPE/FGV). E-mail: zzambosa@yahoo.com.br.

Frederico Lustosa da Costa é doutor em gestão pelo Instituto Universitário de Lisboa (ISCTE) e professor do Programa de Pós-graduação em Administração (PPGAd) da Universidade Federal Fluminense (UFF). E-mail: fredericolustosa@id.uff.br. 